\section{Immunolocalization of succinate dehydrogenase in the esophagus epithelium of domesticated mammals}

\author{
W. Meyer, ${ }^{1}$ J. Kacza, ${ }^{2}$ I. N. Hornickel, ${ }^{1}$ \\ B. Schoennagel ${ }^{1}$ \\ 'Institute for Anatomy, University of \\ Veterinary Medicine Hannover \\ Foundation, Hannover; \\ ${ }^{2}$ Institute of Anatomy, Histology and \\ Embryology, Faculty of Veterinary \\ Medicine, University of Leipzig, Germany
}

\begin{abstract}
Using immunohistochemistry and transmission electron microscopy (TEM), the esophagus epithelia of seven domesticated mammals (horse, cattle, goat, pig, dog, laboratory rat, cat) of three nutrition groups (herbivorous, omnivorous, carnivorous) were studied to get first information about energy generation, as demonstrated by succinate dehydrogenase (SDH) activities. Distinct reaction intensities could be observed in all esophageal cell layers of the different species studied reflecting moderate to strong metabolic activities. The generally strong staining in the stratum basale indicated that new cells are continuously produced. The latter feature was confirmed by a thick, and in the horse generally highly active stratum spinosum. Only in the pig, reaction intensity variations occurred, obviously related to differences in physical feed quality or restricted feed allocation. The immunohistochemical results were corroborated by the presence of intact mitochondria in the esophageal cells of all species and nutrition types studied, except for the horse. Possible relationships between SDH reaction intensities and feed structure, mass or consistency are discussed.
\end{abstract}

\section{Introduction}

The specific functions of the esophagus epithelium are often regarded as being of minor importance. However, this interesting histological system is normally confronted with a number of challenges, such as mechanical stress from heterogeneous nutrition types, toxic food components and, particularly, microorganisms during the transfer of food..$^{1,2}$ In view of the fact that such incrementing influences result in the necessity of a fast and continuously responding innate immune defence, as shown previously for domesticated mammals, constantly high energy demands can be expected to maintaining a first line of defence mechanisms (with e.g., pathogen recognition receptors, such as Toll-like receptors, or cationic antimicrobial peptides with defensins and cathelicidins) of the innate immune system, contributing also to a microbial homeostasis on the surface of the esophageal epithelium. ${ }^{2}$

Moreover, the structure of the esophagus epithelium of mammalian species belonging to three great nutrition groups (herbivorous, omnivorous, carnivorous) includes several group-specific details based on varying chemical or mechanical influences exerted by the feed. ${ }^{2}$ In this context, we aimed to compare the occurrence and distribution patterns of the energy converting substance succinate dehydrogenase (electron transport chain complex II) as studied using immunohistochemistry. This complex has gained renewed interest due to the discovery of its role in diseases, ${ }^{3}$ but generally because it differs from the other three major complexes (complex I: NADH:UQ oxidoreductase; complex III: cytochrome bc $1 / 2$ complex; complex IV: cytochrome c oxidase) in several important ways: firstly, all proteins of complex II are nuclear encoded, secondly, complex II is a direct enzymatic component of the tricarboxylic acid (TCA) cycle, catalysing the oxidation of succinate to fumarate, thirdly, in contrast with the other complexes, its reaction cycle does not result in proton translocation (for review, Rich and Maréchal $\left.{ }^{4}\right)$. In total, the succinate dehydrogenase complex has proven to be an important cellular driving force of cellular activities, being a good representative of the fact that mitochondrial function is essential for cell survival. ${ }^{5}$ To confirm the immunohistochemical results obtained, the Zeiss Libra 120 with its high contrast imaging technique $(\mathrm{HCI})^{6}$ was used to detect intact mitochondria within the cytoplasm of the cells of the different esophageal epithelial layers.

Realizing that until now, to our knowledge, functional or structural energy-related features have not been investigated in the esophagus epithelium, we believe it is necessary to know more about the basics of energy generation development specifically correlated with nutrition type and transport along the esophagus epithelium. For example, our findings could help to understand how the basal epithelial cells meet cellular energy demands during cell renewal indirectly as caused, for example, by cell loss at the luminal surface as related to the different feed types or structures. Thus, first information will be available concerning energy metabolism in this mechanically very stressed system of the anterior part of the alimentary canal.
Correspondence: Prof. Dr. Wilfried Meyer, Institute for Anatomy, University of Veterinary Medicine Hannover Foundation, Bischofsholer Damm 15, 30173 Hannover, Germany. Tel. +49.511.8567214 - Fax: + 49.511.8567683. E-mail: wilfried.meyer@tiho-hannover.de

Key words: esophagus epithelium, succinate dehydrogenase, domesticated mammals, immunohistochemistry.

Acknowledgments: the excellent technical assistance of M. Gaehle, D. Walter and K. Rohn is gratefully acknowledged. The authors greatly appreciate the help of all colleagues at the different institutes or clinics of the University of Veterinary Medicine Hannover Foundation, and of several small animal practioners in Hannover and the abattoir in Gleidingen to obtain the esophagus samples. This study was supported by a grant from the $\mathrm{H}$. Wilhelm Schaumann Foundation, Hamburg, Germany.

Received for publication: 31 January 2013. Accepted for publication: 15 April 2013.

This work is licensed under a Creative Commons Attribution NonCommercial 3.0 License (CC BYNC 3.0).

(C) Copyright W. Meyer et al., 2013

Licensee PAGEPress, Italy

European Journal of Histochemistry 2013; 57:e18 doi:10.4081/ejh.2013.e18

\section{Materials and Methods}

Esophageal samples were collected from seven domesticated mammalian species to include the three major nutrition groups: herbivores - horses (mixed breeds; 6 geldings, 5 females), cattle (Holstein Friesian; 4 females), goats (mixed breeds; 1 male, 4 females); omnivores - pigs (German landrace; 15 females), dogs (mixed breeds, German shepherd dog, beagle; it has to be added that the canid diets are among the most versatile in carnivores, varying from strictly carnivorous to some that contain less than $5 \%$ protein ${ }^{7}$ ), laboratory rats (Fischer 344, Lewis, from Charles River, Sulzfeld, Germany; 8 females, 65 days old); carnivores - cat (mixed breeds; 4 males, 4 females). The samples were obtained and taken at the Institute for Anatomy, the Institute for Physiology, the Institute for Animal Nutrition, the Institute for Parasitology, the Institute for Pharmacology, Toxicology and Pharmacy, and the Small Animal Clinic of the University of Veterinary Medicine Hannover Foundation, or several small animal practitioners and one abattoir in Hannover and its surroundings. All animals had to be euthanized for veterinary medical reasons or were controls of research 
projects (laboratory rats); none of the animals used had suffered from diseases related to the intestinal tract. The esophagus was opened by careful dissection and six to seven small samples (maximum $1 \mathrm{~cm}^{3}$ ) were excised. The samples were taken from the mid-region of the esophagus, because prior studies of all of the animals used ${ }^{2,8,9}$ had demonstrated that no regional differences in structure existed related to the epithelium.

Immediately after excision, the sample blocks were transferred into the two fixation media chosen, Bouin's solution: ${ }^{10}$ fixation for $48 \mathrm{~h}$, afterwards washing several times in $70 \%$ ethanol with the addition of some drops of ammonia (conc.) to remove the picric acid, and stored in $80 \%$ ethanol; Ca-acetate buffered formalin: ${ }^{11}$ fixation for $24 \mathrm{~h}$, afterwards washing several times in 70\% ethanol, and storage in $70 \%$ ethanol. The influences of fixation media have been studied and discussed by Hornickel et al., ${ }^{9}$ whereby Bouin`s solution had produced the best results concerning protein fixation and relevant localization of the substances studied. ${ }^{12}$ After careful dehydration, the material was embedded via xylene in paraffin wax (Paraplast plus, Covidien, Neustadt, Germany).

Eight $\mu \mathrm{m}$ paraffin sections were deparaffinized in xylene and hydrated through descending concentrations of ethanol. Afterwards, these sections were stained immunohistochemically for the determination of succinate dehydrogenase (subunit A, SDHA; dilutions 1:1000, 1:1200; antibovine, from mouse; BioLogo, Kronshagen, Germany). Following incubation over night at $4^{\circ} \mathrm{C}$, the reaction was detected by the EnVision ${ }^{\circledR}$ system (DakoCytomation, Hamburg, Germany), using a peroxidase-based and very sensitive dextranpolymer visualization. One part of the sections was incubated for $30 \mathrm{~min}$ in TEC (Tris-EDTAcitrate) buffer at $90^{\circ} \mathrm{C}$ prior to the reaction.

To conduct the negative controls, the first antibody was omitted and instead the tissue was incubated with PBS / 1\% BSA. In order to exclude the possibility of non-specific binding of the Fc-part of the primary antibody, isotype controls were conducted, ${ }^{9}$ whereby the primary antibody was omitted and replaced by an IgG of mouse or rabbit antibody (Sigma). The respective protein concentration of the antibody was considered, i.e., the IgG mouse antibody was applied in the same protein concentration as the primary antibody. To evaluate non-specific binding potentially caused by sources other than the primary antibody, tissue sections were also stained with just the secondary antibody followed by application of the visualization system. Endogenous peroxidase activity was blocked by an incubation of the samples in an $80 \%$ ethanol solution with $\mathrm{H}_{2} \mathrm{O}_{2}(197 \mathrm{~mL}$ $80 \%$ ethanol $+3 \mathrm{~mL} 30 \% \mathrm{H}_{2} \mathrm{O}_{2}$ ) for $30 \mathrm{~min}$ during the rehydration process).${ }^{9}$ For light microscopical structural analysis, paraffin sections were stained with hematoxylineosin. ${ }^{10}$ All sections of the esophagus samples were analyzed using a Zeiss Photomicroscope II with a digital camera (Olympus DP70).

The transmission electron microscopy (TEM) was used to control the presence of mitochondria in the cells of the different layers of the esophagus epithelium. Small pieces of the esophagus, excluding the tunica muscularis, were fixed for $48 \mathrm{~h}$ in Karnovsky's fluid ${ }^{13}$ immediately after sampling, washed several times in PBS, and postfixed in buffered 1\% osmium tetroxide (Sigma-Aldrich, St. Louis, MO, USA) ${ }^{14}$ for $2 \mathrm{~h}$. After careful dehydration in graded ethanol, the samples were embedded in
Epon 812 (Serva Electrophoresis, Heidelberg, Germany) ${ }^{15}$ and cut with a diamond knife on the ultramicrotome Ultracut E (Leica Microsystems, Wetzlar, Germany). Thin sections ( $<70 \mathrm{~nm})$ stained with methanolic uranyl acetate (Sigma-Aldrich) ${ }^{16}$ and lead citrate (Sigma-Aldrich) ${ }^{17}$ were viewed in the Zeiss (Carl Zeiss, Jena, Germany) Libra 120 energy filter electron microscope (EFTEM), operated at $120 \mathrm{kV}$. Additionally, unstained thin sections were viewed in the EFTEM using the high contrast imaging (HCI) system. For light microscopical control of the TEM material, semithin sections were routinely stained with $0.2 \%$ toluidine blue $0^{18}$ and analyzed using a Zeiss Photomicroscope II with a digital camera (Olympus DP70).

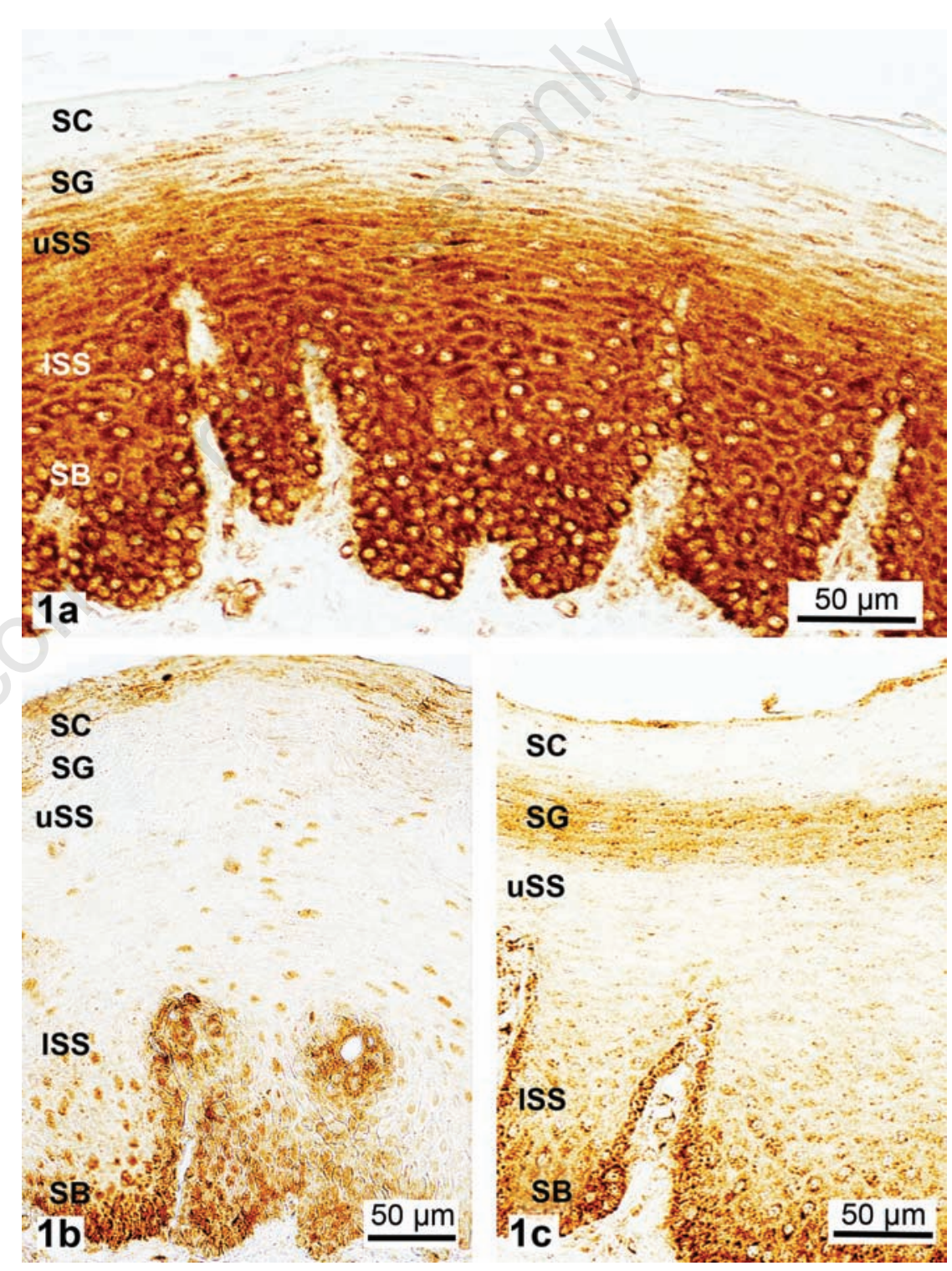

Figure 1. Succinate dehydrogenase reaction intensities in the esophagus epithelium of herbivorous domestic mammals; (a) horse, (b) cattle, (c) goat. SB, stratum basale; ISS, lower stratum spinosum; uSS, upper stratum spinosum; SG, stratum granulosum; SC, stratum corneum; DAB visualization. 


\section{Results}

The general structure of the esophagus displayed no differences when the seven domesticated species studied were compared using the light microscopy (LM) or TEM results for analysis. The staining of the succinate dehydrogenase produced several species or nutrition related variations of labelling intensity and is summarized in the Figures 1,2 and 3 and Table 1. The esophageal epithelial layers of the three main nutrition groups studied, firstly, revealed a generally strong reaction intensity concerning the stratum basale. The labelling was most obvious in the horse (Figure 1a), whereas the cattle and the goat showed somewhat varying staining intensities, clearly observable only in the basal cell layer (Figure 1 b,c). However, the most striking finding comparing the three herbivorous species was the difference of staining intensity observed in the following stratum spinosum, demonstrating a rather homogeneous strong labelling in the lower and upper parts of this layer exclusively in the horse (Figure 1a). On the contrary, in the cattle and the goat the spinosal cell staining was only moderate to weak. The most outer epithelial layers, stratum granulosum and stratum corneum, revealed a weakly positive reaction staining (Figure $1 \mathrm{~b}, \mathrm{c}$ ), although in the horse it was restricted to the granulosal cells.

In the omnivorous species studied, the intensity of immunohistochemical labelling varied between pig, dog, and laboratory rat (Figure 2). This means that it was generally strong and clearly observable in the stratum basale, and to some extent also in the spinosal and granulosal cells of the latter two species, particularly concerning the rat, but the reaction staining was found to be only weak or even negative in these cells regarding the pig. However, in this animal, a positive immunohistochemical labelling of medium to strong intensity appeared in the multilayered stratum corneum (Table 1; Figure 2a), although not

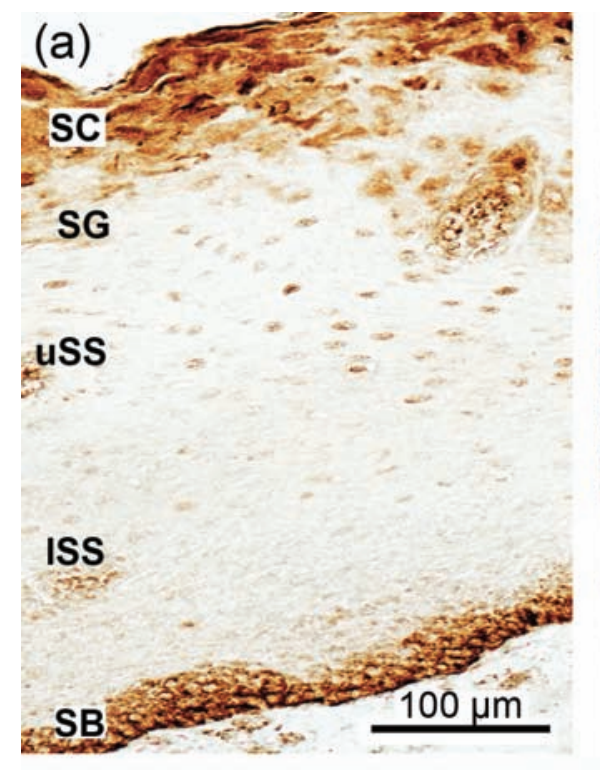

\section{(b)}

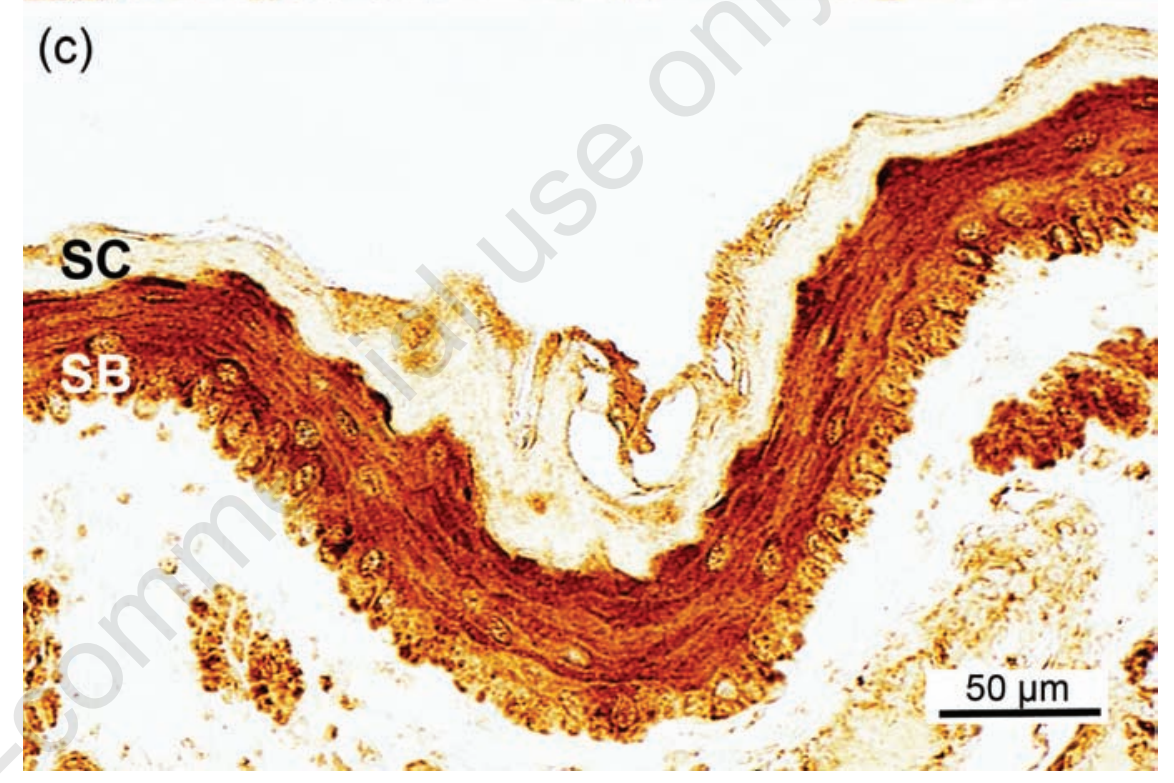

Figure 2. Succinate dehydrogenase reaction intensities in the esophagus epithelium of omnivorous domestic mammals; (a) pig, (b) dog, (c) laboratory rat. SB, stratum basale; SS, stratum spinosum; ISS, lower stratum spinosum; uSS, upper stratum spinosum; SG, stratum granulosum; SC, stratum corneum; DAB visualization.

Table 1. Comparative immunohistochemical labeling intensity of succinate dehydrogenase in the esophagus epithelium of domesticated mammals.

$\begin{array}{lccccc}\text { Species } & \text { Str. corneum } & \text { Str. granulosum } & \text { Str. spinosum (upper) } & \text { Str. spinosum (lower) } & \text { Str. basale } \\ \text { Herbivorous } & & & 3-4 & 4 & 4 \\ \quad \text { Horse } & 0 & 0-2 & 0-2 & 2-3 & 4 \\ \text { Cattle } & 0-2 & 0-2 & 1-2 & 2-3 & 4 \\ \text { Goat } & 0-1 & 2 & 1-2 & 1-3 & 4 \\ \text { Omnivorous } & 0-4 & 0-3 & 3 & 3-4 & 4 \\ \text { Pig } & 0-3 & 1-3 & 3-4 & 3-4 & 4 \\ \text { Dog } & 0-1 & 3-4 & 2-4 & \end{array}$

Reaction intensities: 0, no reaction; 1, very weak; 2 , weak; 3 , medium; 4, strong 
continuously. This means that in the porcine esophagus sometimes low metabolic activity occurred, during which positive reaction staining for succinate dehydrogenase was completely confined to the cells of the stratum basale.

The thin esophagus epithelium of the carnivorous cat revealed positive reactions for succinate dehydrogenase in all strata, where it was homogeneously of medium to strong intensity (Figure 3). This observation includes that even the stratum corneum showed a weak to medium staining reaction, except for its most outer flat cells.

The findings obtained from the immunohistochemical demonstration of succinate dehydrogenase in the esophagus epithelium were confirmed by observations made by TEM application (HCI technique; Figures 4 and 5) regarding the presence of mitochondria. From a more general view, it became obvious that in all of the esophageal strata in the domesticated mammals studied, the outer layers always showed intact nuclei (e.g., dog and cat), but also increasing numbers of degenerating or pycnotic nuclei, residual bodies and multivesicular bodies, especially when herbivorous species were concerned (e.g., horse and cattle). Combined with distinctly positive reactions for succinate dehydrogenase, the pig exhibited, besides intact mitochondria, also liposomes, multivesicular bodies and autophagosomes or residual bodies in cells of the outer stratum corneum.

\section{Discussion}

The intensities of succinate dehydrogenase activity observed in the epithelial cell layers of the esophagus of the different domesticated mammals studied reflect varying metabolic activities, to some extent presuming that their is a positive linear correlation of the rate of oxygen consumption with cell volume and cell protein content. ${ }^{19}$ Moreover, relationships between feed structure or feed mass and energy demands are emphasized. This means that the generally strong staining reactions in the cells of the stratum basale corroborate the view that the basic layer system continuously produces new cells, whereby energy production seemed to be activated in the most distinct manner, only in the horse, the laboratory rat, and the cat. Independent of the fact that all herbivorous species were equipped with a thick multilayered esophageal epithelium, the horse revealed strong reactions for succinate dehydrogenase in the entire stratum spinosum, whereas the stratum corneum showed no positive staining. Such findings may indicate effects of mechanical stress by the feed type or

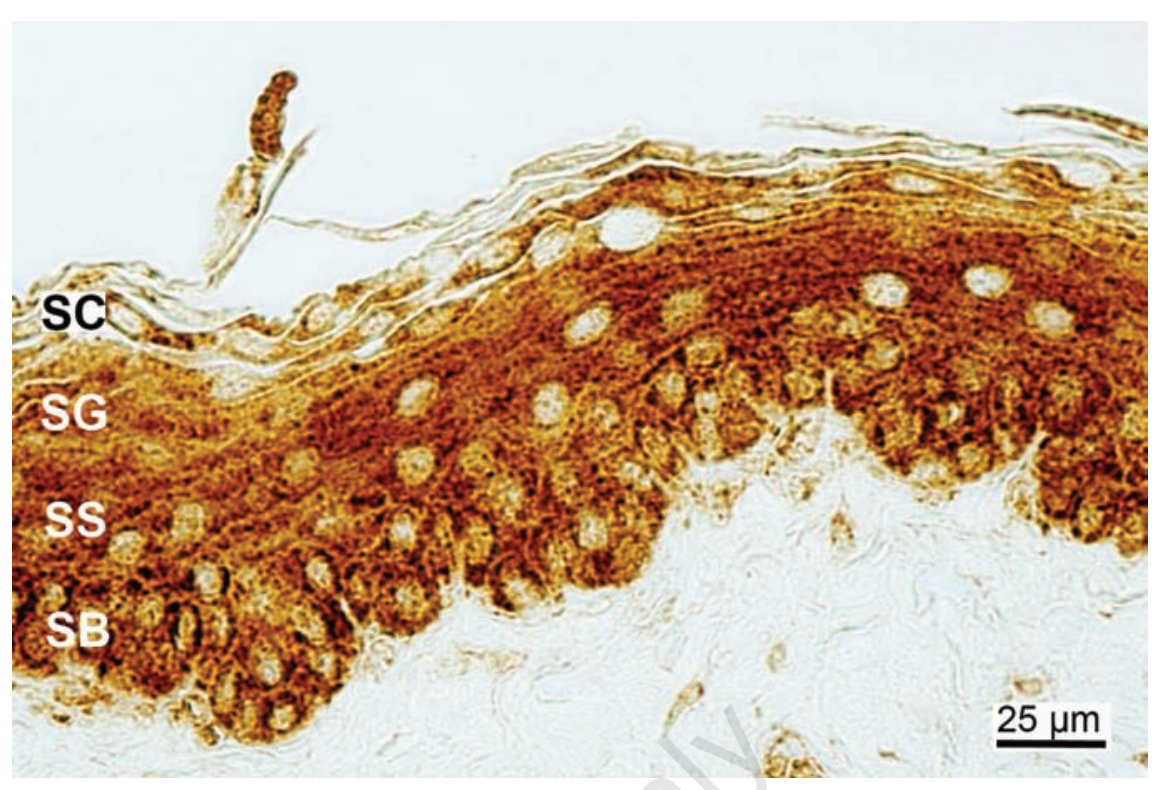

Figure 3. Succinate dehydrogenase reaction intensities in the thin esophagus epithelium of the carnivorous cat. SB, stratum basale; SS, stratum spinosum; SG, stratum granulosum; SC, stratum corneum; DAB visualization.

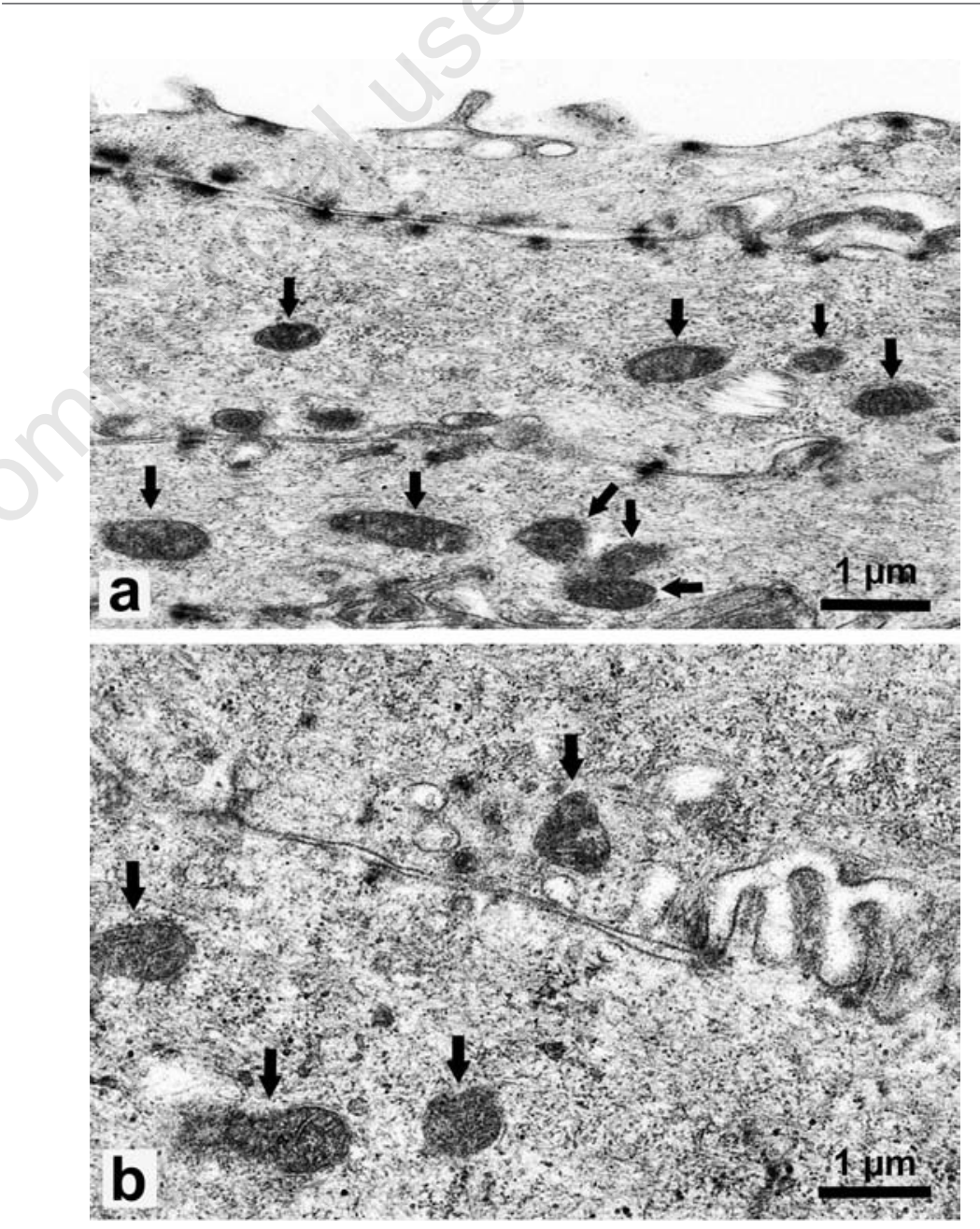

Figure 4. Transmission electron microscopy examples of mitochondria (arrows) in cells of the outer stratum corneum of the esophagus epithelium of the $\operatorname{dog}(a)$ and the cat (b); Zeiss Libra 120, HCI imaging. 
feed mass, so that a continuous supply of strain withstanding corneal cells is necessary to protect the integrity of the most outer layer system. The latter aspect is especially important realizing that the surface of the esophagus epithelium is characterized by a dense cover of microorganisms. ${ }^{1,2}$ Concerning the loss of mitochondria in the equine corneal cells, new findings have confirmed that in mammalian systems degradation of mitochondria via autophagy (mitophagy) not only takes place in response of damaged mitochondria but also may play a critical role in pathophysiological responses associated with cellular stress (see above) (review by Goldman et $a l .^{20}$ ). Regarding the mainly negative results obtained for any presence of different substances of innate immunity in the equine cornea cells, ${ }^{2}$ the finding of intracellular and/or exocytotic vesicles in these cells may rather be related to a constant production of complex glycoconjugates. ${ }^{1}$

In contrast to the nonruminant horse, the ruminant herbivorous species studied revealed a slight but distinct decrease of succinate dehydrogenase activities from the stratum basale to the stratum corneum, often additionally displaying positive reactions in the corneal cells, as supported by the TEM demonstration of intact mitochondria. Our findings are generally confirmed by results from the few earlier studies on the distribution of oxidative enzymes in the ruminant esophagus epithelium based on enzyme histochemistry. ${ }^{21,22}$ The difference between both groups can be explained by the observation that nonruminant ungulates with hindgut fermentation, such as the Equidae, in contrast to the cattle or goats are capable to consume food of low nutritive value and compensate its low digestibility by use of a great mass of forage, that may exert great strain for the esophagus epithelium. ${ }^{23}$ Regarding the related high pressure on the esophageal layers, it seems that, as in other soft tissues, both intracellular and extracellular resistances may increase.$^{24}$ In like manner, cellular mitochondrial biogenesis is enhanced by focal adhesion kinase in response to the mechanical stress, as shown for cardiomyocytes. $^{25}$

Among the omnivorous and the carnivorous species studied, succinate dehydrogenase activities and intact mitochondria could be detected in all epithelial layers including the stratum corneum. The pig, particularly, revealed areas with positive and negative enzyme stainings, that may reflect variations of restricted feed allocation or physical feed quality, as related with differences in energy needs. To some extent, such phenomenon emphasizes an adaptation of the esophagus to nutrition and luminal factors, as discussed for the enterocytes of the small intestine. ${ }^{26}$ This means that the magnitude and potential of intestinal nutrient absorption and defence function are regulated by metabolic learning. Nevertheless, it seems that mechanical strain is of minor importance in the pig, and probably compensated by the thick stratum spinosum. Such view is supported by the fact that in this species grinding intensity or crude fibre contents do not affect macroscopic lesion scores of the esophagus epithelium, including a synergistic effect of both factors on preventing lesions in the gastric mucosa. ${ }^{27}$

The medium to strong succinate dehydrogenase reactions observed also in the upper strata of the thin esophageal epithelia of the other omnivorous species (dog, rat) studied and of the carnivorous cat, accompanied by observations of several intact mitochondria within the cells, firstly, might reflect the physiological response to mechanical stress and, secondly, be indicative for cell renewal activation by the stratum basale. In the rat, for example, very small pointed wood pieces (length about 100 $\mu \mathrm{m}$ ), probably deriving from the litter (cryo SEM observation by the authors, not shown), may be the cause. For the dog and the cat, in particular, the consistency and the size of the nutrition or nutrition parts, respectively, could be relevant factors.

Summarizing all aspects discussed, it can be concluded that the immunohistochemical labeling intensities of succinate dehydogenase observed in the different epithelial cell layers of the esophagus of the different species studied clearly reflect varying metabolic activities, emphasizing relationships between feed structure, feed consistency or feed mass and the energy generation rates. Moreover, the length and intensity of rumination activities may be of influence in cattle or sheep and goats to some extent.

\section{References}

1. Meyer W, Kacza J, Schnapper A, Verspohl J, Hornickel IN, Seeger J,. A first report on the microbial colonisation of the equine oesophagus. Ann Anatomy 2010;192:42-51.

2. Hornickel IN, Kacza J, Schnapper A, Beyerbach M, Schoennagel B, Seeger J, Meyer W. Demonstration of substances of innate immunity in the esophagus epithelium of domesticated mammals. Part II. Defence mechanisms, including species comparison. Acta Histochem 2011;113: 175-88.

3. Rutter J, Winge DR, Schiffman JD. Succinate dehydrogenase. Assembly regulation and role in human disease. Mitochondrion 2010;10:393-401.

4. Rich PR, Maréchal A. The mitochondrial respiratory chain. Essays Biochem 2010; 47:1-23.

5. Parsons MJ, Green RG. Mitochondria in cell death. Essays Biochem 2010;47:99-114.

6. Reimer L. Electron spectroscopic imaging. In: L. Reimer (ed.) Energy FilteringTransmission Electron Microscopy. Springer, 1995, pp. 347-93.

7. Sillero-Zubiri S. Family Canidae. In: D.E. Wilson, R.A. Mittermeier (eds.) Handbook of the mammals of the world, vol. 1, Carnivores. Lynx Edition, Barcelona, Spain, 2009, pp. 352-446.

8. Schoennagel B. Vergleichende Untersuchungen zur Struktur und Funktion des Oesophagus-Epithels bei Vertebraten in Bezug zur Ernaehrungsweise, unter besonderer Beruecksichtigung der Haussaeugetiere. Ph.D. Thesis, Univ Vet Med Hannover, Germany, 2005.

9. Hornickel IN, Kacza J, Schnapper A, Beyerbach M, Schoennagel B, Seeger J, Meyer W. Demonstration of substances of innate immunity in the esophagus epithelium of domesticated mammals. Part I. Methods and comparative fixation evaluation. Acta Histochem 2011;113:163-74.

10. Boeck P. Romeis Mikroskopische Technik. 17th ed., Urban und Schwarzenberg, Muenchen, Germany, 1989.

11. Lillie RD, Fullmer HM. Histopathologic technic and practical histochemistry. McGraw-Hill, New York, USA, 1976.

12. Pearse AGE. Histochemistry, Theoretical and Applied. 4th. ed. vol. 2: Analytical technology. Churchill Livingstone, 1985.

13. Karnovsky MJ. A formaldehyde-glutaraldehyde fixative of high osmolality for use in electron microscopy. J Cell Biol 1965;27: 137A-8A.

14. Millonig G. Advantages of a phosphate buffer for $0 \mathrm{s04}$ solutions in fixation. $\mathrm{J}$ Appl Phys 1961;32:1637.

15. Luft JH. Improvements in epoxy resin embedding methods. J Biophys Biochem Cytol 1961;9:409-14.

16. Stempak JG, Ward RT. An improved staining method for electron microscopy. J Cell Biol 1964;22:697-701.

17. Reynolds ES. The use of lead citrate of high $\mathrm{pH}$ as an electron opaque stain in electron microscopy. J Cell Biol 1963;17: 208-12.

18. Richardson KC, Jarett L, Finke EH. Embedding in epoxy resins for ultrathin sectioning in electron microscopy. Stain Technol 1960;35:313-23.

19. Wagner BA, Venkataraman S, Buettner GR. The rate of oxygen utilization by cells. Free Rad Biol Med 2011;51:700-12.

20. Goldman SJ, Taylor R, Zhang Y, Jin S. Autophagy and the degradation of mitochondria. Mitochondrion 2010;10:309-15. 
21. Ramkrishna V, Tiwari GP, Bhattacharya M, 24. Dodde RE, Bull JL, Shih AJ. Bioimpedance Saigal RP. Dehydrogenases in the epithelium of oesophagus and forestomach of adult buffalo. Ind J Anim Sci 1987;57:20-5.

22. Soveri T, Lindberg LA. Histochemistry of the forestomach epithelium of the reindeer calf. Acta Histochem 1993;95:117-24.

23. von Engelhardt W, Breves G. Physiologie der Haustiere, 3rd ed. Enke Publ., Stuttgart, Germany, 2009. of soft tissue under compression. Physiol Meas 2012;33:1095-109.

25. Tornatore TF, Costa AP, Clemente CFMZ, Judice C, Rocco SA, Calegari VC, et al. A role for focal adhesion kinase in cardiac mitochondrial biogenesis induced by mechanical stress. Am J Physiol Heart Circ Physiol 2011;300:H902-12.

26. Schmitz G, Langmann T. Metabolic learn- ing in the intestine: Adaptation to nutrition and luminal factors. Horm Metabol Res 2006;38:452-54.

27. Millet S, Meyns T, Aluwé M, De Brabander D, Ducatelle R. Effect of grinding intensity and crude fibre content of the feed on growth performance and gastric mucosa integrity of growing-finishing pigs. Livestock Sci 2010;134:152-54. 